\title{
Structure-Activity-Relationship and Bioactivity of Neurotrophic trans-Banglene
}

\author{
Khyati Gohil,`M. Zain H. Kazmi,`Florence J. Williams*» \\ ${ }^{\diamond}$ Department of Chemistry, University of Iowa, Iowa City, IA, USA 52246 \\ - Department of Chemistry, University of Alberta, Edmonton, AB, Canada T6G 2G2 \\ KEYWORDS neurotrophic, bioactive natural product, TrkA signaling, NGF signaling, structure-activity relationship
}

\begin{abstract}
Neurotrophic small molecule natural products are functional analogs of signaling proteins called neurotrophins, which cause a pro-growth, pro-survival, or pro-differentiation response in neuronal cells. While these phenotypic responses are desirable to combat neurodegenerative disease progression, neurotrophin proteins possess pharmacokinetic properties that present challenges to their administration in living organisms, whether in biomedical studies or as therapeutics. Small molecules such as the cis- and trans-banglenes offer attractive alternatives to activate neurotrophic responses. We describe the synthesis and testing of banglene derivatives to establish a structure-activity response for the banglene family. Notably, during the course of our studies trans-banglene was shown to cause nerve growth factor (NGF)-potentiated neuritogenesis that was markedly stronger than the neuritogenic effects of trans-banglene alone. We demonstrate that only $(-)$ trans-banglene is active, while its $(+)$ enantiomer is not, and further demonstrate that select modifications on the cyclohexene ring of trans-banglene does not impair its bioactivity. Finally, to probe the relationship between (-) trans-banglene's mechanism of action and canonical NGF signal transduction pathways, we employed kinase inhibitors targeting Pkc, Akt1/2/3 and Erk1/2, designed to inhibit NGF-induced neurotrophic signaling. Interestingly, (-) trans-banglene potentiation of NGF-induced neuritogenesis was unaffected by the presence of these kinase inhibitors. Collectively, these results suggest a dual-mode of action for (-) trans-banglene (both neurotrophic alone and strongly potentiating of NGF activity), and an independence of its potentiating action on Pkc and Erk1/2 enzymatic activity.
\end{abstract}

\section{INTRODUCTION}

Neurodegenerative diseases, which include Alzheimer's and Parkinson's disease, are characterized by the progressive loss of neuronal function, degeneration of neuronal structure, and decrease in brain mass. ${ }^{1}$ Despite an imminent societal need, neurodegenerative diseases have been resistant to effective therapeutic development to date. As an example, the clinical trial failure rate for new drugs has exceeded $90 \%$ over the past two decades and no current treatment for Alzheimer's disease extends life span. ${ }^{2}$ This situation stresses a need for a diverse approach in identifying therapeutic targets.

Our lab has been intrigued by the potential of neurotrophic small molecules in this medicinal area. Neurotrophic molecules are functional analogs of natural signaling proteins called neurotrophins [e.g. nerve growth factor (NGF)], which trigger proliferation, differentiation, growth, and/or regeneration in neurons or neuronal progenitor cells. ${ }^{4}$ Neurotrophin proteins have been demonstrated to increase neuron cell resistance to the cytotoxic activity of amyloid Beta $(\mathrm{A} \beta)$ and tau, ${ }^{5-6}$ to increase neurogeneration, ${ }^{7}$ and to improve memory and learning in animal models of neurodegenerative diseases. ${ }^{8}$ However, neurotrophin proteins have short half-lives in blood and serum, and do not cross the blood-brain barrier (BBB), ${ }^{9}$ presenting significant challenges to administration. Small molecules which trigger similar phenotypic responses could readily address these pharmacokinetic limitations while providing similar therapeutic impact. Such molecules also constitute unique biochemical tools to modulate neurotrophic responses.

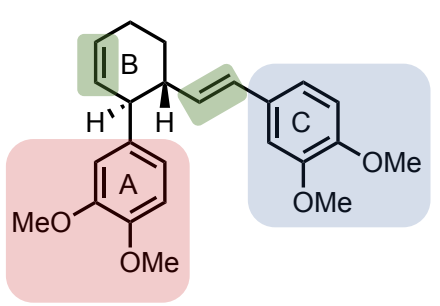

Figure 1. Sites of modification in the trans-banglene structure - substitution on the two benzene rings, hydrogenation state of both alkenes and the $\mathrm{E} / \mathrm{Z}$ isomers of the styrenyl alkene

One set of neurotrophic molecules of interest are the cisand trans- banglenes $(c-\mathrm{BG}$ and $t$-BG, $t$-BG shown in Figure $1)$. These phenylbutenoid dimers are isolated from the medicinal ginger Zingiber purpureum, also called Zingiber cassumunar. ${ }^{10}$ Cis- and trans-banglenes exhibit neurotrophic activity in primary rat neurons and neurogenic activity in neurodegenerative mouse models. They have been shown to be orally bioavailable in mice and in humans, and to readily cross the blood-brain barrier in mouse studies. ${ }^{11}$ Safety profiling of extracts of Zingiber purpureum demonstrated no-adverse effects to human subjects taking $850 \mathrm{mg}$ /day for four weeks, which corresponds to $50 \mathrm{mg}$ of cis- and trans-banglene. ${ }^{12}$ In addition, cis and trans-banglene are readily accessible synthetically. ${ }^{10,13}$

Despite demonstrated bioactivity, bioavailability and safety data, there are significant gaps in mechanistic and molecular understanding of banglene activity. Structural features 
<smiles>C=CC=Cc1ccc(OC)c(OC)c1</smiles>

1a

2a

3a<smiles>COc1ccc(/C=C/C=C/c2ccc(OC)c(OC)c2)cc1/C=C/c1ccc(OC)c(OC)c1</smiles>

Scheme 1. Synthetic access to $t$-BG and $c$-BG through Diels-Alder dimerization.
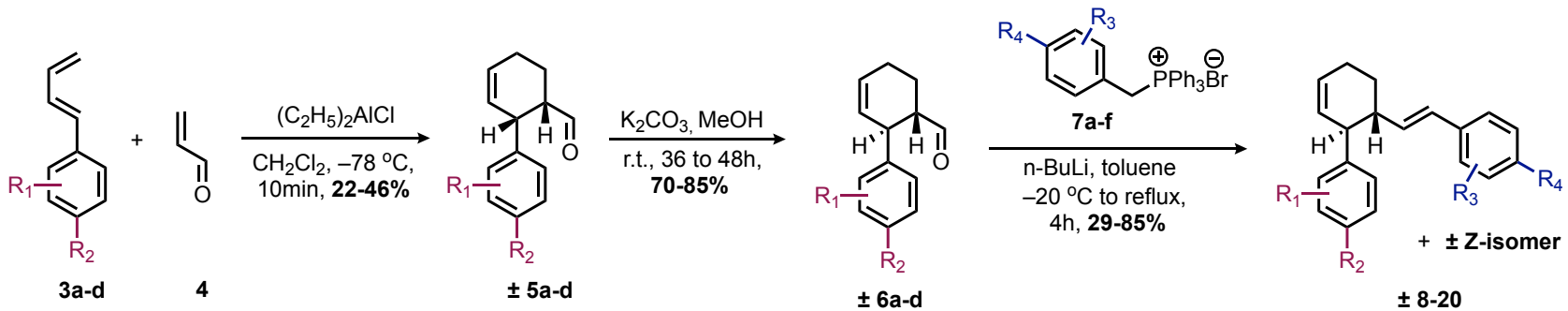

Scheme 2. Synthetic access to derivatives with distinct A and $\mathrm{C}$ ring modifications using a Wittig olefination.<smiles>COc1ccc([C@H]2C=CCC[C@H]2/C=C/c2ccccc2)cc1OC</smiles>

$8 \mathrm{R}=\mathrm{H}$

$9 \mathrm{R}=m-\mathrm{OMe}$

$10 \mathrm{R}=p-\mathrm{OMe}$

$11 \mathrm{R}=0-\mathrm{Me}$

$12 \mathrm{R}=\mathrm{o}-\mathrm{Br}$<smiles>COc1ccc(C=CC2CCCC[C@H]2c2ccc(OC)c(OC)c2)cc1OC</smiles>

$\pm 24$

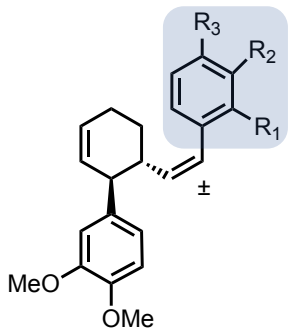

$13 \mathrm{R}_{1}=\mathrm{H}, \mathrm{R}_{2}=\mathrm{OMe}, \mathrm{R}_{3}=\mathrm{OMe}$ $14 R_{1}=H, R_{2}=O M e, R_{3}=H$ $15 \mathrm{R}_{1}=\mathrm{H}, \mathrm{R}_{2}=\mathrm{H}, \mathrm{R}_{3}=\mathrm{OMe}$ $16 R_{1}=M e, R_{2}=H, R_{3}=H$

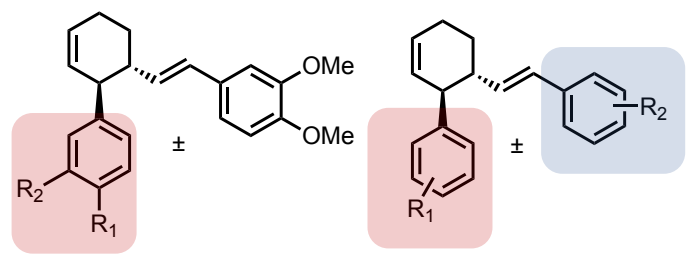

$17 \mathrm{R}_{1}=\mathrm{H}, \mathrm{R}_{2}=\mathrm{OMe}$ $18 \mathrm{R}_{1}=\mathrm{OMe}, \mathrm{R}_{2}=\mathrm{H}$ $19 \mathrm{R}_{1}=\mathrm{OH}, \mathrm{R}_{2}=\mathrm{OMe}$
$20 \mathrm{R}_{1}, \mathrm{R}_{2}=m-\mathrm{OMe}$, $21 \mathrm{R}_{1}, \mathrm{R}_{2}=p-\mathrm{OMe}$

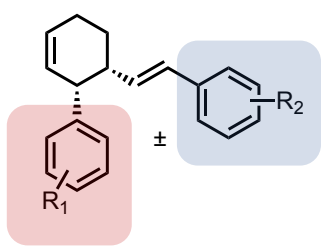

$22 \mathrm{R}_{1}, \mathrm{R}_{2}=m-\mathrm{OMe}$ $23 \mathrm{R}_{1}, \mathrm{R}_{2}=p-\mathrm{OMe}$<smiles>COc1ccc(/C=C/C2CCCC[C@H]2c2ccc(OC)c(OC)c2)cc1OC</smiles><smiles>CCOC(=O)C1[C@H]2CC[C@H](/C=C/c3ccc(OC)c(OC)c3)[C@H](c3ccc(OC)c(OC)c3)[C@H]12</smiles><smiles>CCOC(=O)C1C2CC[C@H](/C=C/c3ccc(OC)c(OC)c3)[C@H](c3ccc(OC)c(OC)c3)[C@@H]21</smiles>

Figure 2. Banglene derivatives for investigation of their neurotrophic

responsible for the neurotrophic activity of the banglenes have not yet been identified and neurotrophic testing has been performed exclusively with racemic mixtures. Further, it is unclear whether banglenes intercept NGF-related signal transduction pathways or if they operate through distinct mechanisms.

This work describes preliminary structure-neurotrophic activity relationship investigations for trans-banglene, including the testing of all stereoisomers. Additionally, a series of PC 12 neuritogenesis tests explore the impact of trans-banglene on canonical neurotrophic signaling pathways.

\section{RESULTS AND DISCUSSION}

\section{Chemical Synthesis}

Cis- and trans-banglene ( $\boldsymbol{c}$-BG and $\boldsymbol{t}$-BG) were synthesized using a reported Diels-Alder dimerization from diene 3 . $^{10}$ Diene 3 was accessed from 3,4-dimethoxybenzaldehyde 1 using zinc-mediated allylation followed by a mesylation and elimination of the resulting benzylic alcohol. The Diels-Alder cycloaddition provided a mixture of cis- and trans-banglene with no apparent endo/exo selectivity, as previously reported. ${ }^{10}$ All stereoisomers were separated using reverse-phase HPLC. 
This strategy was also used to generate derivatives with identical substitution patterns on the $\mathrm{A}$ and $\mathrm{C}$ rings (20-23).

Twelve more derivatives of the banglene scaffold were generated using a Wittig reaction with cyclohexene aldehydes 5ad, allowing for differential substitution on the two aromatic rings $(\mathrm{A}$ and $\mathrm{C}$ ) of the banglene structure.

Interestingly, Horner-Wadsworth-Emmons reactions proved unsuccessful with trans-aldehyde 6a, despite success with ciscompound $\mathbf{5 a}$, which is consistent with previous reporting by Lim and coworkers.

Further derivatization of the cyclohexene ring of transbanglene was achieved through a palladium-catalyzed hydrogenation or a rhodium-catalyzed cyclopropanation, generating compounds 24-27.

The enantiomers of compounds 8-17, and $\mathbf{2 3}$ were separated by chiral chromatography.

\section{PC 12 Neuritogenesis Assays}

Cis-banglene was observed to crystallize and precipitate out of cell media at $30 \mu \mu \mathrm{M}$ concentration (DMEM $+5 \% \mathrm{HS}+5 \% \mathrm{FBS}$, see Supporting Info). Therefore, cell assay studies focused on trans-banglene, which showed no solubility challenges at $30 \mu \mathrm{M}$.

Though modest compared to NGF, synthetic trans-banglene caused statistically significant increases in PC 12 neuritogenesis, as shown in Figure $3 \mathrm{~b}$. Interestingly, the combined treatment of trans-banglene and NGF resulted in strongly augmented neuritogenesis levels, demonstrating a potentiating effect of trans-banglene. ${ }^{14}$ Average cell body area was also increased in relation to increased neuritogenesis levels (Figure 3c). a.

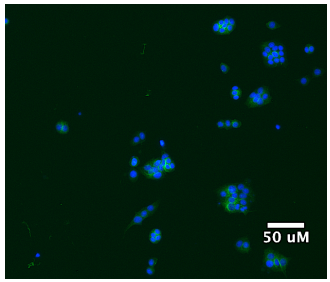

DMSO

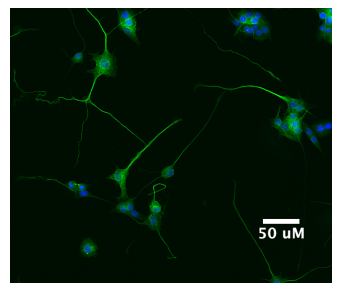

NGF $10 \mathrm{ng} / \mathrm{mL}$

b.

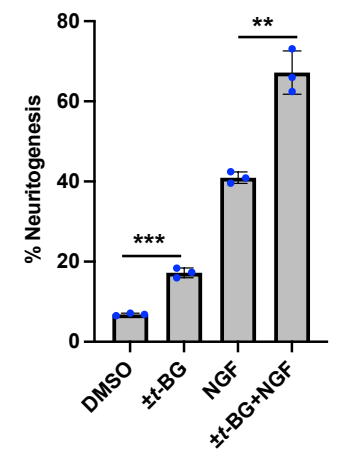

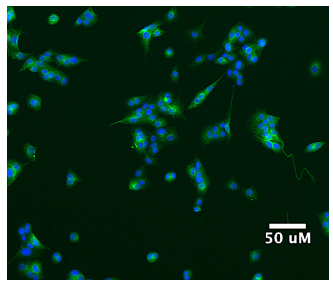

$\pm t-\mathrm{BG}(30 \mu \mathrm{M})$

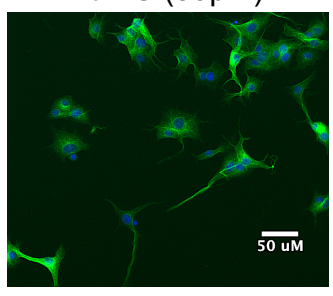

$\pm t-\mathrm{BG}+\mathrm{NGF}$

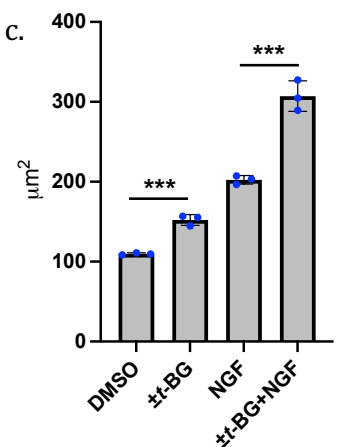

Figure 3. a) Neuritogenesis cell assays in PC 12 cell line. PC 12 cells were cultured in DMEM containing 5\% FBS $+5 \% \mathrm{HS}$, after $24 \mathrm{~h}$ the media was changed to DMEM containing $2 \% \mathrm{HS}+1 \%$ FBS and cells were treated as follows: DMSO (control, $0.6 \%$ ), $\pm \boldsymbol{t}$ BG $(30 \mu \mathrm{M}+0.6 \%$ DMSO $)$, NGF $(10 \mathrm{ng} / \mathrm{mL}+0.6 \%$ DMSO $)$, and $\pm \boldsymbol{t}$-BG $+\mathrm{NGF}(30 \mu \mathrm{M} \boldsymbol{t}$-BG $+10 \mathrm{ng} / \mathrm{mL} \mathrm{NGF}+0.6 \%$ DMSO). After $48 \mathrm{~h}$ of treatment, cells were fixed, stained with Hoescht stain (nuclei, blue) and labelled with anti- $\beta$-tubulin III antibody (cell body, green) for visualization and analysis on metaXpress HCA (10x). (b) \%Neuritogenesis post treatment was calculated as a percentage of total number of cells that had neurites $>$ $5 \mu \mathrm{m}$. (c) Average cell body area measured for each treatment. pvalue measured by unpaired t-test $* * * \mathrm{p}<0.001, * * \mathrm{p}<0.01$.

Given the electron-rich aromatic rings in the banglene structure, banglenes could act as antioxidants. To establish whether the neuritogenesis effects observed were due to non-specific antioxidant activity, tocopherol acetate (acetylated vitamin E) and trans-resveratrol were both evaluated in the PC 12 neuritogenesis assay. These two antioxidants were chosen for their chemical similarity to banglenes: tocopherol acetate is lipophilic $(\log \mathrm{P}=10.9),{ }^{15}$ and trans-resveratrol has electron-rich styrenyl aromatic rings. While trans-resveratrol treatment resulted in minor increases in neuritogenesis levels, neither antioxidant appeared to have similar activity to trans-banglene (Figure 4a). a.

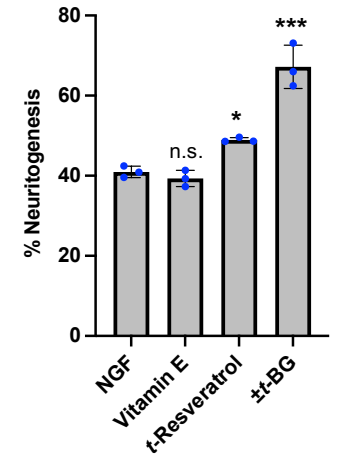

C.

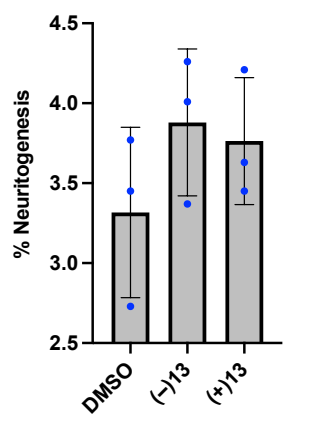

b.

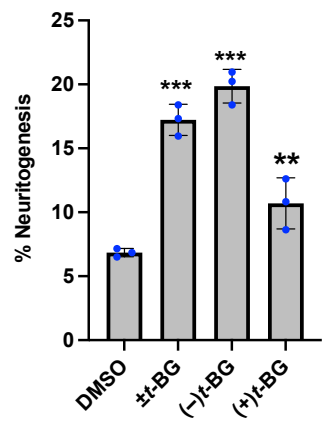

d.

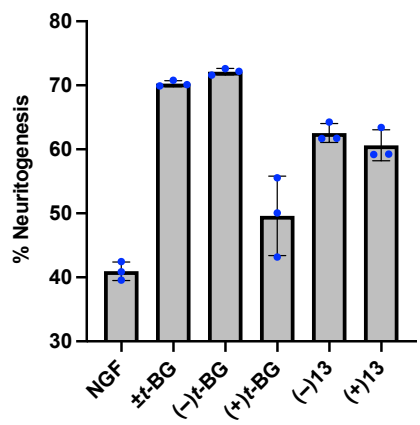

Figure 4. Quantification of neuritogenesis in PC 12 cells assays (a) Effect of common antioxidants when tested at $30 \mu \mathrm{M}$ in the presence of $10 \mathrm{ng} / \mathrm{mL}$ of NGF (b) Trend of neuritogenesis after treatment of $30 \mu \mathrm{M}$ of racemic: $\pm \boldsymbol{t}$-BG and individual enantiomers: $(-) \boldsymbol{t}$-BG, $(+) \boldsymbol{t}$-BG (c) Neuritogenesis levels after treatment with $30 \mu \mathrm{M} \mathrm{Z}$ derivatives (-)13 and $(+) \mathbf{1 3}$ (d) NGF neuritogenesis potentiation: all compounds were tested at $30 \mu \mathrm{M}$ in the presence of $10 \mathrm{ng} / \mathrm{mL}$ of NGF. \%Neuritogenesis post treatment was calculated as a percentage of total number of cells that had neurites $>5$ $\mu \mathrm{m}$. p-value measured by ANOVA followed by Dunnett's multiple comparison test vs. DMSO (b. and c.) and NGF (a and d) ${ }^{*} p<0.05$, $* * * \mathrm{p}<0.001$. 


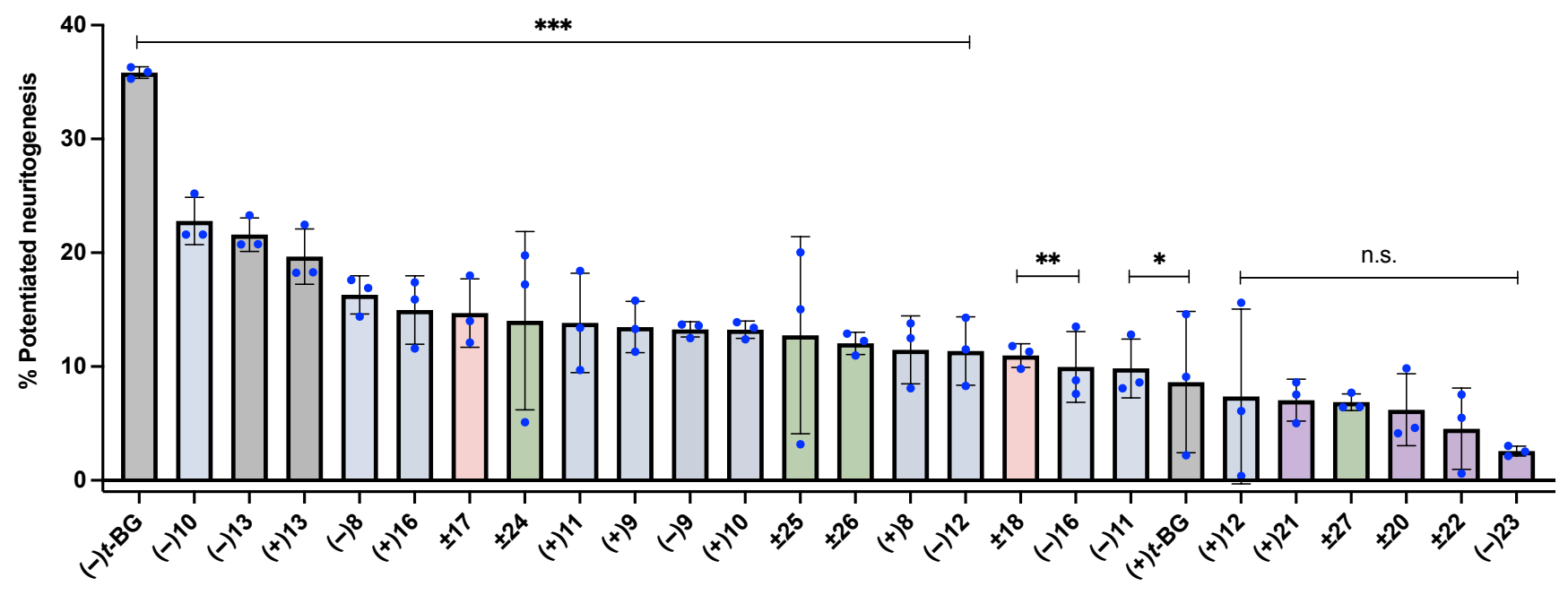

Figure 5. Neuritogenesis potentiated by analogues in the presence of NGF. All compounds were tested at $30 \mu \mathrm{M}$ along with $10 \mathrm{ng} / \mathrm{mL}$ of NGF and $0.6 \%$ DMSO. Compounds which did not cause potentiated neuritogenesis are not shown. \%Neuritogenesis post treatment was calculated as a percentage of total number of cells that had neurites $>5 \mu \mathrm{m}$. \%Potentiated neuritogenesis $=\%$ neuritogensis $(30 \mu \mathrm{M}$ compound $+10 \mathrm{ng} / \mathrm{mL} \mathrm{NGF}$ ) - \%neuritogenesis (10 ng/mL NGF). p-value measured by ANOVA followed by Dunnett's multiple comparison test vs. NGF $* \mathrm{p}<0.05,{ }^{*} \mathrm{p}<0.01, * * * \mathrm{p}<0.001$. Colors reflect the location of $\boldsymbol{t}$-BG modification for each derivative tested. Blue $=\mathrm{A}$ ring; green $=\mathrm{B}$ ring; red $=\mathrm{C}$ ring; purple $=$ both $\mathrm{A}$ and $\mathrm{C}$ rings.

All stereoisomers of trans-banglene were then separately tested for activity, both alone and in combination with NGF treatment. (-) trans-banglene is observed to be the active enantiomer, with an NGF potentiation $\mathrm{EC}_{50}=14 \pm 1 \mu \mathrm{M}$, while $(+)$ trans-banglene causes minimal neurotrophic effects in these studies. Interestingly, $\mathrm{Z}$ alkene isomers of transbanglene, $(+) \mathbf{1 3}$ and $(-) \mathbf{1 3}$, both exhibited potentiating effects in the presence of NGF but did not increase differentiation and neurite outgrowth when administered in the absence of NGF.

Collectively, these results show that the activity of transbanglene is structure dependent, increasing the likelihood of a specific recognition event in the PC 12 cell. Prior to this work, the enantiomers of trans-banglene had only been tested for P-glycoprotein (Pgp) antagonist activity. ${ }^{13}$

Synthetic derivatives of trans-banglene were screened first for NGF-potentiating activity (Figure 5). While (-) transbanglene elicited the largest neuritogenesis increases, many derivatives were identified with statistically significant potentiating effects. Modifications were tolerated on either the A or C rings, but modifications on both resulted in loss of activity. Changes to the substitution pattern of the A ring was particularly well tolerated, with all $E$-alkene isomer derivatives demonstrating potentiating activity. Compound 19, the only derivative with a hydroxyl group, positioned on the $\mathrm{C}$ ring, resulted in high levels of cell death.

Modification of the two alkenes of trans-banglene was also tolerated. Importantly, cis-banglene derivatives $\mathbf{2 5}$ and $\mathbf{2 7}$ were observed to be soluble in media at $30 \mu \mathrm{M}$ concentrations. The conformationally flexible hydrogenated derivatives $\mathbf{2 4}$ and $\mathbf{2 5}$ resulted in a decrease of potentiation effects by roughly half. Cyclopropanation of the $\mathrm{B}$ ring, which in contrast retains rigidity similar to that of an alkene, was tolerated for trans derivative 25 but also resulted in a similar decrease in potentiating effects.

Given these activity trends, we examined the most active derivative, (-)10, its ring A analog 18, hydrogenated trans- derivative 25, and cyclopropyl ester derivative $\mathbf{2 6}$ for neuritogenesis effects in the absence of NGF. Interestingly, only compounds 25 and 26 demonstrated neurotrophic activity in this assay. Therefore, modifications to the substitution patterns on the $\mathrm{A}$ and $\mathrm{C}$ rings appear to abrogate neurotrophic activity, despite being tolerated for NGF potentiation responses. Further, the lack of neurotrophic activity of Z-alkene derivatives $(-) \mathbf{1 3}$ and $(+) \mathbf{1 3}$ also demonstrates that neurotrophic activity is sensitive to styrenyl alkene geometry.

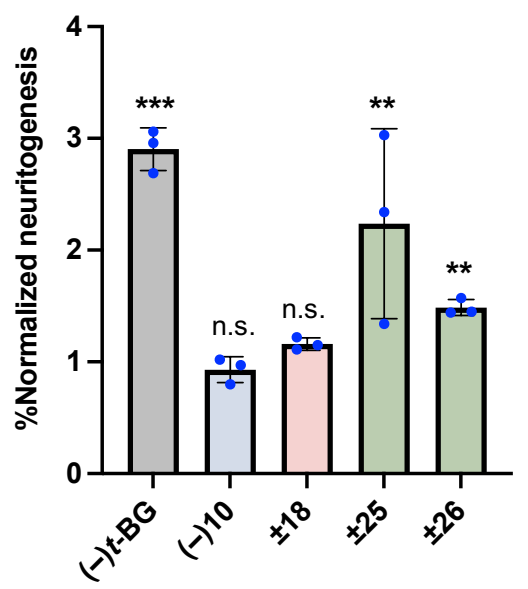

Figure 6. \%Normalized neuritogenesis after treatment with 30 $\mu \mathrm{M}$ derivatives of trans-Banglene for $48 \mathrm{~h}+0.6 \%$ DMSO. $\%$ Neuritogenesis was calculated as a percentage of total number of cells that had neurites $>5 \mu \mathrm{m}$. \%Normalized neuritogenesis was calculated as \%neurotogenesis (Compound) / \%neuritogenesis (DMSO), p-value measured by unpaired t-test, values compared to control (DMSO), $* \mathrm{p}<0.05, * * \mathrm{p}<0.01, * * * \mathrm{p}<0.001$

\section{Chemical Inhibitor Testing}

The potentiating effect of (-) trans-banglene suggests that it facilitates NGF-mediated signal transduction either directly or 
by increasing the expression of cell machinery or transcription factors necessary for NGF-mediated neuritogenesis.

Canonical NGF neurotrophic signal transduction is initiated by the binding of NGF to tropomyosin receptor kinase A (TrkA, Figure 7a). TrkA undergoes autophosphorylation which in turn initiates signal transduction through protein kinase $\mathrm{C}(\mathrm{Pkc})$, protein kinase $\mathrm{B}(\mathrm{Akt} / \mathrm{Pkb})$, and/or mitogen activated protein kinases (Raf, Mek, Erk). TrkA activation of these kinases is associated with neural plasticity, cell survival, and differentiation responses, respectively. ${ }^{16-17}$

To investigate the effect that trans-banglene has on TrkAinitiated signal transduction in each of these parallel pathways, NGF-induced neuritogenesis levels were measured in the presence of three chemical inhibitors, triciribine (iAkt), Gö 6983 (iPkc), and SCH772984 (iErk). Triciribine inhibits the phosphorylation, and subsequent activation, of Akt1/2/3. ${ }^{18}$ Triciribine binds to the Akt pleckstrin homology $(\mathrm{PH})$ domain and prevents the localization of Akt to the plasma membrane, which is required for phosphorylation and activation of Akt by Pdk1. Gö 6983 is a Pkc inhibitor, and acts as a competitive inhibitor of ATP binding. ${ }^{19}$ Gö 6983 has been shown to be pan-specific, inhibiting the $\alpha, \beta, \gamma$, and $\delta$ isoforms of Pkc. ${ }^{20}$ SCH772984 is also a competitive inhibitor of ATP binding, but for Erk1/2. Despite similar mechanisms, Gö 6983 and SCH772984 have demonstrated high specificity for their target kinases, with the latter having been tested on over 300 different kinases. ${ }^{21}$
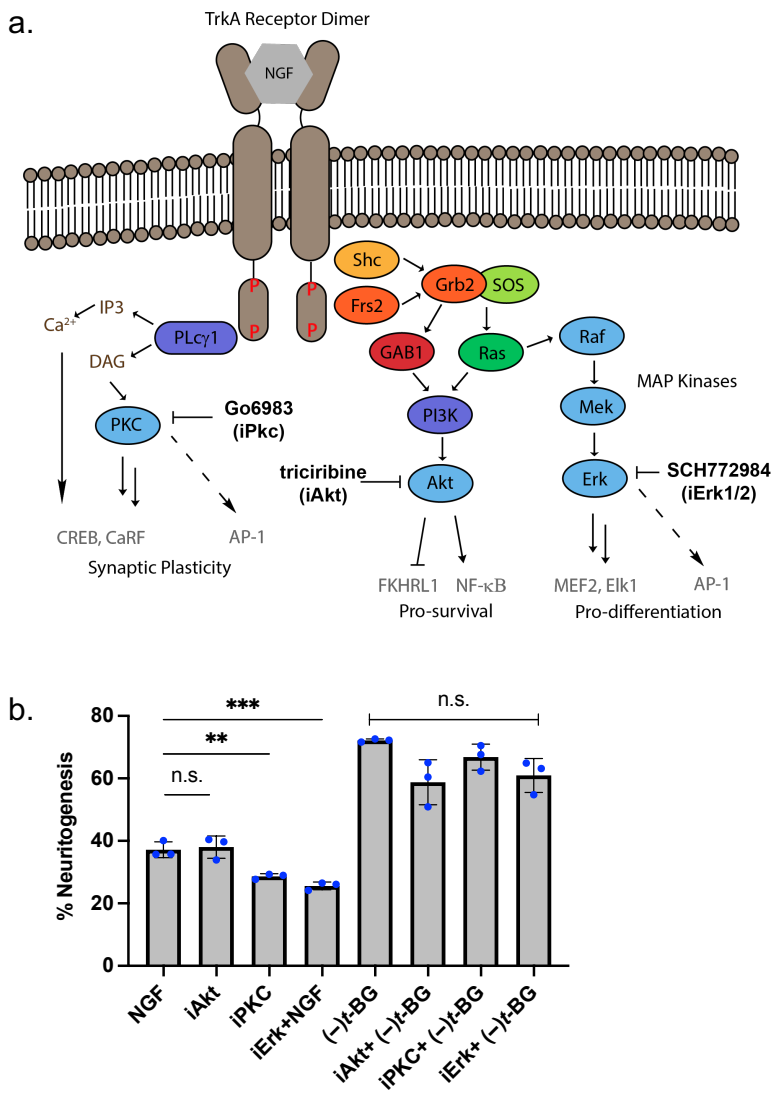

Figure 7. (a) NGF-mediated signal transduction pathways with sites of inhibitor action. (b) Effect of pathway inhibitors on NGF $(10 \mathrm{ng} / \mathrm{mL}+0.6 \% \mathrm{DMSO})$ and $(-) \boldsymbol{t}$-BG $(30 \mu \mathrm{M}+10 \mathrm{ng} / \mathrm{mL} \mathrm{NGF}$ $+0.6 \% \mathrm{DMSO}$ ) signaling. $\mathrm{p}$-value measured by ANOVA followed by Dunnett's multiple comparison test $* * p<0.01, * * * p<0.001$.
Inhibition of Pkc and Erk activity by Gö 6983 (iPkc) and SCH772984 (iErk) resulted in a significant decrease in NGFinduced neuritogenesis observed in PC 12 cells. However, inhibition of Akt activity by triciribine treatment (iAkt) did not result in a similar decrease in neuritogenesis levels. This is consistent with NGF-mediated Akt activation being associated with cell survival. Cell survival phenotypes are often independent of neuritogenesis responses. ${ }^{16}$ In contrast, Pkc and Erk activation is associated with neural plasticity and differentiation, which directly involve neurite outgrowth. ${ }^{17}$

Interestingly, (-)trans-banglene treatment rescued NGFinduced neuritogenesis levels in the presence of these inhibitors and further resulted in potentiated neuritogenesis that was statistically similar to levels observed in the absence of the inhibitors. These response data indicate that the potentiating activity of (-)trans-banglene is not expressly reliant on Pkc or Erk activity.

\section{CONCLUSIONS}

Structure dependency for activity is a hallmark of a discrete cellular target. Only one enantiomer of trans-banglene demonstrated neurotrophic activity and strong potentiating activity. However, structure-activity studies also revealed that the degree of potentiating activity for banglene derivatives is not proportional to neurotrophic activity in the absence of NGF. This lack of correlation becomes clear when comparing derivatives $\mathbf{9}, \mathbf{1 2}, \mathbf{1 3}, \mathbf{1 7}, \mathbf{2 4}$, and $\mathbf{2 5}$. Such differences in structureactivity response constitute evidence of dual-function, and further, may be the result of a dual-mechanism for (-) transbanglene action.

An important consideration in exploring the mechanism of (-) trans-banglene activity is whether TrkA is a likely target for (-) trans-banglene recognition. Other small molecules have been identified that modulate TrkA activity, whether in the presence or absence of NGF protein. Gambogic amide is known to activate TrkA autophosphorylation and subsequent signal transduction, ${ }^{22}$ while sarcodonin $G$ potentiates NGF activity by increasing TrkA's binding affinity for NGF. ${ }^{23}$ If () trans-banglene was able to both activate TrkA and modulate TrkA binding affinity to NGF, then structural changes that improve NGF potentiation might not correlate with improvements in direct TrkA activation, consistent with observed differences in structure-activity relationship studies in the presence and absence of NGF protein.

However, the lack of sensitivity of (-)trans-banglene potentiating effects to pan-Pkc and Erk1/2 inhibitors, which should dampen the effects of TrkA signal transduction, is inconsistent with TrkA as a cellular target of (-) trans-banglene. Pkc and Mek inhibitors strongly suppress the potentiation of NGF activity by sarcodonin $\mathrm{G}$, for example. ${ }^{23}$

Similarly, if potentiation effects are the result of increased cellular production of NGF (or proNGF), such potentiating effects should also be sensitive to chemical inhibitors of Pkc and Erk proteins. These results suggest that $(-)$ trans-banglene either activates neuritogenic signaling responses that are downstream of Pkc and Erk, or that are independent of canonical NGF signal transduction pathways.

Neurotrophin signaling is complex, involving signal transduction pathways that include kinases responsible for numerous cell environmental response actions. ${ }^{24}$ Further, neurotrophin recognition initiates a variety phenotype changes, including increased synapse formation, neurogenesis, survival and 
resilience, and increased proliferation. ${ }^{17}$ This complexity and nuanced signal transduction setting demands precise chemical and biochemical tools for its study, particularly in the context of neurodegenerative disease. Annotated mechanisms of action for neurotrophic molecules like (-) trans-banglene will allow for their use as tools to further neurotrophic signaling investigations.

While the exact details of the mechanism of (-) transbanglene remain unclear, this work has established the design principles for mechanistic probe development. Further, this work makes clear that there are two different modes in which (-) trans-banglene can act on a cell - in the absence or presence of NGF protein. Finally, chemical inhibtion of Pkc and Erk demonstrates that traditional TrkA/NGF activated kinases are not central to NGF-dependent (-) trans-banglene action.

Of particular promise is the discovery that cyclopropyl ester 25 exhibits both neurotrophic and NGF-potentiating activity. The ester of $\mathbf{2 5}$ is primed for the conjugation of mechanistic reporters or cross-linking functionality that can facilitate cellular target identification. Such studies constitute immediate future work to further the annotation of (-) trans-banglene's mechanism of action.

\section{ASSOCIATED CONTENT}

\section{Supporting Information}

Supporting information document A includes synthetic protocols, characterization data for all compounds (including purity and enantio-enrichment data), HPLC traces, PC 12 cell assay protocols and dose response study of (-) $t$-BG.

Supporting information document B includes NMR spectra

\section{AUTHOR INFORMATION}

\section{Corresponding Author}

* Prof. Florence J. Williams

Department of Chemistry

University of Iowa

Iowa City, Iowa, 52242 (USA)

E-mail: florence-williams@uiowa.edu

\section{Author Contributions}

KG performed synthesis of 8-18 and 20-23 compounds as well as all cell culture and biological testing. MZK performed the synthesis of 19 and 24-27.

The manuscript was written by KG and FJW. / All authors have given approval to the final version of the manuscript.

\section{Funding Sources}

This work was supported by the Canada Research Coordinating Committee NFRFE-2018-00223, the Canadian Foundation for Innovation IOF-34997, the University of Alberta and the University of Iowa.

\section{ACKNOWLEDGMENT}

The authors would like to thank Gareth Lambkin for advice and maintenance of shared cell culture facilities. We would also like to thank Prof. Robert Campbell and the Campbell lab for the donation of select cell culture consumables, as well as Lotus Separations for separating the enantiomers of $t$-BG and the PhenoLogix applications team at Phenomenex for developing the chiral HPLC method for separating enantiomers of banglene derivatives.

\section{ABBREVIATIONS}

NGF, nerve growth factor; $\mathrm{A} \beta$, amyloid Beta; $\mathrm{BBB}$, blood-brain barrier; HCA, high content analyser; Trk A, tropomyosin receptor kinase $\mathrm{A}$; Pkc, protein kinase $\mathrm{C}$, $\mathrm{Pkb}$, protein kinase

\section{REFERENCES}

1. Dugger, B. N.; Dickson, D. W., Pathology of Neurodegenerative Diseases. Cold Spring Harb Perspect Biol 2017, 9 (7), a028035.

2. Cummings, J. L.; Morstorf, T.; Zhong, K. J. A. s. R.; Therapy, Alzheimer's disease drug-development pipeline: few candidates, frequent failures. Alzheimer's Res. Ther 2014, 6 (4), 37.

3. Reichardt, L. F., Neurotrophin-regulated signalling pathways. Philos. Trans. R. Soc. Lond., B, Biol. Sci. 2006, 361 (1473), $1545-1564$.

4. Xu, J.; Lacoske, M. H.; Theodorakis, E. A., Neurotrophic natural products: chemistry and biology. Angew Chem Int Ed 2014, $53(4), 956-87$.

5. $\quad \mathrm{Su}, \mathrm{R} . ; \mathrm{Su}, \mathrm{W} . ;$ Jiao, Q., NGF protects neuroblastoma cells against $\beta$-amyloid-induced apoptosis via the $\mathrm{Nrf} 2 / \mathrm{HO}-1$ pathway. FEBS Open Bio 2019, 9 (12), 2063-2071.

6. Jiao, S. S.; Shen, L. L.; Zhu, C.; Bu, X. L.; Liu, Y. H.; Liu, C. H.; Yao, X. Q.; Zhang, L. L.; Zhou, H. D.; Walker, D. G.; Tan, J.; Gotz, J.; Zhou, X. F.; Wang, Y. J., Brain-derived neurotrophic factor protects against tau-related neurodegeneration of Alzheimer/'s disease. Transl Psychiatry 2016, 6, e907.

7. Zigova, T.; Pencea, V.; Wiegand, S. J.; Luskin, M. B., Intraventricular Administration of BDNF Increases the Number of Newly Generated Neurons in the Adult Olfactory Bulb. Mol. Cell. Neurosci 1998, 11 (4), 234-245.

8. Nagahara, A. H.; Merrill, D. A.; Coppola, G.; Tsukada, S.; Schroeder, B. E.; Shaked, G. M.; Wang, L.; Blesch, A.; Kim, A.; Conner, J. M.; Rockenstein, E.; Chao, M. V.; Koo, E. H.; Geschwind, D.; Masliah, E.; Chiba, A. A.; Tuszynski, M. H., Neuroprotective effects of brain-derived neurotrophic factor in rodent and primate models of Alzheimer's disease. Nat Med 2009, 15 (3), 331-337.

9. Pan, W.; Banks, W. A.; Kastin, A. J., Permeability of the blood-brain barrier to neurotrophins. Brain Res 1998, 788.

10. Tuntiwachwuttikul, P.; Limchawfar, B.; Reutrakul, V.; Kusamran, K.; Byrne, L., Syntheses of some constituents of Zingiber cassumunar. Aust. J. Chem 1980, 33 (4), 913-916.

11. Matsui, N.; Kido, Y.; Okada, H.; Kubo, M.; Nakai, M.; Fukuishi, N.; Fukuyama, Y.; Akagi, M., Phenylbutenoid dimers isolated from Zingiber purpureum exert neurotrophic effects on cultured neurons and enhance hippocampal neurogenesis in olfactory bulbectomized mice. Neurosci Lett 2012, 513 (1), 72-7.

12. Kato, E.; Kubo, M.; Okamoto, Y.; Matsunaga, Y.; Kyo, H.; Suzuki, N.; Uebaba, K.; Fukuyama, Y., Safety Assessment of Bangle (Zingiber purpureum Rosc.) Rhizome Extract: Acute and Chronic Studies in Rats and Clinical Studies in Human. ACS Omega 2018, 3 (11), 15879-15889.

13. Chu, J.; Suh, D. H.; Lee, G.; Han, A. R.; Chae, S. W.; Lee, H. J.; Seo, E. K.; Lim, H. J., Synthesis and biological activity of optically active phenylbutenoid dimers. J Nat Prod 2011, 74 (8), 1817-21.

14. Yanagimoto, T.; Kishimoto, S.; Kasai, Y.; Matsui, N.; Kubo, M.; Yamamoto, H.; Fukuyama, Y.; Imagawa, H., Design and synthesis of dual active neovibsanin derivatives based on a chemical structure merging method. Bioorg. Med. Chem. Lett. 2020, 30 (20), 127497 .

15. Pubchem compound summary for CID 1742129, (-)-alphaTocopherol. National Library of Medicine: National Center for Biotechnology Information, 2021.

16. Rai, S. N.; Dilnashin, H.; Birla, H.; Singh, S. S.; Zahra, W.; Rathore, A. S.; Singh, B. K.; Singh, S. P., The Role of PI3K/Akt and ERK in Neurodegenerative Disorders. Neurotox Res 2019, 35 (3), 775-795.

17. Thiele, C. J.; Li, Z.; McKee, A. E., On $<$ em $>$ Trk $</$ em $>$ The TrkB Signal Transduction Pathway Is an Increasingly Important Target in Cancer Biology. Clin 2009, 15 (19), 5962-5967. 
18. Berndt, N.; Yang, H.; Trinczek, B.; Betzi, S.; Zhang, Z.; Wu, B.; Lawrence, N. J.; Pellecchia, M.; Schönbrunn, E.; Cheng, J. Q.; Sebti, S. M., The Akt activation inhibitor TCN-P inhibits Akt phosphorylation by binding to the $\mathrm{PH}$ domain of Akt and blocking its recruitment to the plasma membrane. Cell Death Differ 2010, 17 (11), $1795-1804$

19. Toullec, D.; Pianetti, P.; Coste, H.; Bellevergue, P.; GrandPerret, T.; Ajakane, M.; Baudet, V.; Boissin, P.; Boursier, E.; Loriolle, F., The bisindolylmaleimide GF $109203 \mathrm{X}$ is a potent and selective inhibitor of protein kinase C. J. Biol. Chem. 1991, 266 (24), 15771-15781.

20. Gschwendt, M.; Fürstenberger, G.; Leibersperger, H.; Kittstein, W.; Lindner, D.; Rudolph, C.; Barth, H.; Kleinschroth, J.; Marmé, D.; Schächtele, C.; Marks, F., Lack of an effect of novel inhibitors with high specificity for protein kinase $\mathrm{C}$ on the action of the phorbol ester 12-O-tetradecanoylphorbol-13-acetate on mouse skin in vivo. Carcinogenesis 1995, 16 (1), 107-111.

21. Morris, E. J.; Jha, S.; Restaino, C. R.; Dayananth, P.; Zhu, H.; Cooper, A.; Carr, D.; Deng, Y.; Jin, W.; Black, S.; Long, B.; Liu, J.; DiNunzio, E.; Windsor, W.; Zhang, R.; Zhao, S.; Angagaw, M. H.; Pinheiro, E. M.; Desai, J.; Xiao, L.; Shipps, G.; Hruza, A.; Wang, J.; Kelly, J.; Paliwal, S.; Gao, X.; Babu, B. S.; Zhu, L.; Daublain, P.;
Zhang, L.; Lutterbach, B. A.; Pelletier, M. R.; Philippar, U.; Siliphaivanh, P.; Witter, D.; Kirschmeier, P.; Bishop, W. R.; Hicklin, D.; Gilliland, D. G.; Jayaraman, L.; Zawel, L.; Fawell, S.; Samatar, A. A., Discovery of a Novel ERK Inhibitor with Activity in Models of Acquired Resistance to BRAF and MEK Inhibitors. Cancer Discov 2013, 3 (7), 742-750.

22. Jang, S.-W.; Okada, M.; Sayeed, I.; Xiao, G.; Stein, D.; Jin, P.; Ye, K., Gambogic amide, a selective agonist for TrkA receptor that possesses robust neurotrophic activity, prevents neuronal cell death. Proc. Nat. Acad. Sci. 2007, 104 (41), 16329-16334.

23. Cao, C.-Y.; Zhang, C.-C.; Shi, X.-W.; Li, D.; Cao, W.; Yin, X.; Gao, J.-M., Sarcodonin G Derivatives Exhibit Distinctive Effects on Neurite Outgrowth by Modulating NGF Signaling in PC12 Cells. ACS Chem. Neurosci 2018, 9 (7), 1607-1615.

24. Biarc, J.; Chalkley, R. J.; Burlingame, A. L.; Bradshaw, R. A., The Induction of Serine/Threonine Protein Phosphorylations by a PDGFR/TrkA Chimera in Stably Transfected PC12 Cells. Mol. Cell Proteomics 2012, 11 (5), 15-30. 